\title{
INCLUSÃO DE CRIANÇAS COM SÍNDROME DE DOWN: UM ENSAIO TEÓRICO SOBRE A IMPORTÂNCIA DA RELAÇÃO FAMÍLIA-ESCOLA
}

\author{
Luana Pereira de Novais Silva ${ }^{1}$, Jhenifer Prescilla Dias Fuzinelli ${ }^{2}$, Rosemary Aparecida de Almeida Moraes ${ }^{3}$, \\ Fabiana Frolini Marques Mangili ${ }^{4}$ \\ ${ }^{1}$ Graduada em Pedagogia pela Faculdade Gran Tietê, Barra Bonita, SP. ORCID iD: https://orcid.org/0000-0002-7232- \\ 4755. E-mail: kleriston luana@yahoo.com \\ ${ }^{2}$ Doutoranda em Psicologia do Desenvolvimento e Aprendizagem pela Universidade Estadual Paulista - UNESP, Bauru, \\ SP. Atua como psicóloga responsável pelo Serviço Universitário de Apoio Psicopedagógico (SUAPP) na Universidade do \\ Oeste Paulista - UNOESTE, Jaú, SP e como facilitadora bolsista na Universidade Virtual do Estado de São Paulo - \\ UNIVESP. ORCID iD: https://orcid.org/0000-0002-2672-7641. E-mail: jheniferpsico@gmail.com \\ ${ }^{3}$ Mestre em Literatura e Crítica Literária pela PUC/SP. Professora de Língua Portuguesa e Literatura do Ensino Superior \\ na Gran Tietê, FIP e FAEFI, de Barra Bonita, e PEB II da Secretaria Estadual de Educação de São Paulo na EMTI Dr. \\ Geraldo Pereira de Barros. ORCID iD: https://orcid.org/0000-0002-7029-5364 . E-mail: profmeiremoraes@gmail.com \\ ${ }^{4}$ Graduada em Pedagogia pela Fundação Educacional Dr Raul Bauab, Jaú, SP. Especilização em Psicopedagogia e \\ Docência do Ensino Superior e Técnico. Aposentada como professora da Educação Básica. Professora e Coordenadora \\ do Curso de Pedagogia nas Faculdades Gran Tietê, Barra Bonita, SP e docente na Faculdade Galileu, Botucatu, SP. \\ ORCID iD: https://orcid.org/0000-0001-8581-828X .E-mail: fabianamangili@outlook.com
}

\section{RESUMO}

Frente a temática da inclusão, discussões sobre a importância da relação família-escola são pertinentes no que se refere à socialização das crianças com Síndrome de Down. Nesta perspectiva, o presente ensaio teve como principal objetivo explorar a literatura científica acerca dos desafios encontrados por pais, pela família e por professores no processo de inclusão das crianças com Síndrome de Down. Em específico, este artigo buscou propor discussões sobre a importância da conscientização e colaboração da comunidade para a mudança do paradigma da inclusão. Para tanto, foram selecionados artigos científicos, livros e trabalhos acadêmicos encontrados na base de dados Google Scholar, entre o período de 2010 a 2021 , a partir das seguintes palavras-chave: Pessoas com deficiência; Síndrome de Down; Inclusão; História das pessoas com deficiência; Diagnóstico de filho com deficiência e; Relação Família-Escola. Dentre os principais fatores que influenciam no processo de inclusão da criança com Síndrome de Down, destacam-se crenças e estigmas dos pais, familiares, profissionais da escola e da sociedade sobre a capacidade da criança em lidar com as outras pessoas e aprender, a falta de suporte da família e a falta de apoio/orientação de uma equipe interdisciplinar. A inclusão de pessoas com deficiência ainda se depara com barreiras e desafios que precisam ser rompidos, contudo, por meio da participação ativa da comunidade científica e dos movimentos político-sociais, os estudos a respeito do tema inclusão apontam que as mudanças nesse cenário têm ocorrido de forma gradativa.

Palavras-chave: Pessoa com Deficiência; Síndrome de Down; Relação Escola-Família; Inclusão.

\section{INCLUSION OF CHILDREN WITH DOWN SYNDROME: A THEORETICAL ESSAY ABOUT IMPORTANCE OF THE FAMILY-SCHOOL RELATIONSHIP}

\begin{abstract}
Faced with the theme of inclusion, discussions about the importance of the family-school relationship are relevant with regard to the socialization of children with Down Syndrome. In this perspective, the main objective of this essay was to explore the scientific literature about the challenges faced by parents, family and teachers in the process of inclusion of children with Down syndrome. Specifically, this article sought to propose discussions on the importance of community awareness and collaboration to change the paradigm of inclusion. Therefore, scientific articles, books and academic papers found in the Google Scholar database were selected, between the period 2011 to 2021, based on the following keywords: People with disabilities;
\end{abstract}


Down's syndrome; Inclusion; History of people with disabilities; Diagnosis of a child with a disability and; Family-School Relationship. Among the main factors influencing the inclusion process of children with Down's Syndrome, beliefs and stigmas of parents, family members, school professionals and society about the child's ability to deal with other people and learn, stand out. family support and the lack of support/guidance from an interdisciplinary team. The inclusion of people with disabilities still faces barriers and challenges that need to be overcome, however, through the active participation of the scientific community and political-social movements, studies on the theme of inclusion show that changes in this scenario have occurred gradually.

Keywords: Person with Disabilities; Down's syndrome; School-Family Relationship; Inclusion.

\section{INCLUSIÓN DE NIÑOS CON SÍNDROME DE DOWN: ENSAYO TEÓRICO SOBRE LA IMPORTANCIA DE LA RELACIÓN FAMILIA-ESCUELA}

\section{RESUMEN}

Frente al tema de la inclusión, las discusiones sobre la importancia de la relación familia-escuela son relevantes en lo que respecta a la socialización de los niños con Síndrome de Down. En esta perspectiva, el objetivo principal de este ensayo fue explorar la literatura científica sobre los desafíos que enfrentan los padres, la familia y los docentes en el proceso de inclusión de los niños con síndrome de Down. Específicamente, este artículo buscó proponer discusiones sobre la importancia de la conciencia comunitaria y la colaboración para cambiar el paradigma de la inclusión. Para ello, se seleccionaron artículos científicos, libros y trabajos académicos encontrados en la base de datos de Google Scholar, entre el período 2011 a 2021, en base a las siguientes palabras clave: Personas con discapacidad; Sindrome de Down; Inclusión; Historia de personas con discapacidad; Diagnóstico de un niño con discapacidad y; Relación familia-escuela. Entre los principales factores que influyen en el proceso de inclusión de los niños con Síndrome de Down, se destacan las creencias y estigmas de los padres, familiares, profesionales de la escuela y la sociedad sobre la capacidad del niño para tratar con otras personas y aprender. apoyo / orientación de un equipo interdisciplinario. La inclusión de personas con discapacidad aún enfrenta barreras y desafíos que deben ser superados, sin embargo, a través de la participación activa de la comunidad científica y los movimientos político-sociales, los estudios sobre el tema de la inclusión muestran que los cambios en este escenario se han producido de forma paulatina.

Palabras clave: Persona con Discapacidad; Sindrome de Down; Relación escuela-familia; Inclusión.

\section{INTRODUÇÃO}

O nascimento de uma Pessoa com Deficiência $(P C D)$ é caracterizado por inúmeras mudanças no âmbito familiar, sobretudo, com relação aos pais. De acordo com Sales (2016) quando os pais recebem informações acerca do diagnóstico, o qual afirma que o bebê será uma $P C D$, é comum que os mesmos manifestem reações de negação, seguidas de raiva, barganha ou negociação, culpa e aceitação, sendo este período caracterizado como um processo de luto (LONDERO et al., 2021).

Ao analisar a história das deficiências e a forma como a família e a sociedade as concebia, observa-se alguns marcos importantes. Segundo Fernandes (2011), a princípio, as pessoas que nasciam com deficiência não tinham direito à vida, sendo condenadas à morte e ao abandono pela própria família em locais distantes dos vilarejos. Os períodos seguintes denominaram-se segregação, integração e inclusão. A segregação se refere ao acolhimento das pessoas com deficiência em instituições pautadas em ações assistencialistas, o que reforçou a crença de que a deficiência era um "desvio da normalidade" (FERNANDES, 2011, p. 10). O período da integração é destacado pela inserção das pessoas com deficiência na sociedade e movimentos iniciais em defesa de direitos humanos, corroborando para a existência do terceiro e atual período, a inclusão. Esse último período é caracterizado essencialmente pelos esforços sociais e políticos para a garantia de direitos e ações visando à inclusão em todas as esferas do ser humano.

Neste sentido, a Convenção dos Direitos das Pessoas com Deficiência promovida pela Organização das Nações Unidas é vista como 
outro marco nessa luta, a qual, além de definir o conceito de deficiência, promulgou vieses e políticas inclusivas, dando um salto na garantia dos direitos das pessoas com deficiência (BRASIL, 2015).

\begin{abstract}
Considera-se pessoa com deficiência aquela que apresenta impedimento de longo prazo de natureza física, intelectual, mental, ou sensorial o qual, em interação com uma ou mais barreiras, pode obstruir sua participação plena e efetiva na sociedade em igualdade de condições com as demais pessoas (BRASIL, 2015).
\end{abstract}

Vale ressaltar que as pessoas com deficiência representam $15 \%$ da população mundial, cerca de um bilhão de habitantes, conforme divulgado pela Organização Mundial da Saúde (OMS, 2012) no último Relatório Mundial sobre a Deficiência. No Brasil, de acordo com o último censo realizado pelo Instituto Brasileiro de Geografia e Estatística (IBGE) em 2010, 24\% ou, aproximadamente, 46 milhões de pessoas se identificaram com alguma deficiência. Deste índice, há aproximadamente 300 mil pessoas com Síndrome de Down. Além disso, a pesquisa apontou que das crianças e adolescentes que frequentam creches e escolas do $1^{\circ}$ ao $5^{\circ}$ ano do ensino básico, cerca de 2.611.536 apresentam algum grau de Deficência Intelectual, incluindo os indivíduos com Síndrome de Down (NANTES, 2018).

A

Federação das Associações de Síndrome de Down (2019) aponta que a incidência mundial de crianças que nascem com a Síndrome é de 1 para cada 1000 nascidos anualmente, ou seja, cerca de 3 a 5 mil crianças. No Brasil, estima-se que seja 1 em cada 700 nascimentos, ao passo que nos Estados Unidos, segundo a National Down Syndrome Society (NDSS) a incidência é de 1 para cada 691 nascimentos, havendo aproximadamente 400 mil pessoas com Síndrome de Down.

Sobre isso, Santos (2014) e Mierlo et al.(2018) corroboram ao afirmar que a Síndrome de Down é uma das principais causas de deficiência intelectual, sendo responsável por 18\% das deficiências intelectuais. Coelho (2016, p. 01) explica que a Síndrome de Down é "[...] uma síndrome genética caracterizada por um erro na distribuição dos cromossomos durante a divisão celular do embrião, revertendo na maior parte dos casos, numa trissonomia do cromossomo 21".

O diagnóstico da Síndrome de Down baseia-se na cariotipagem e ultrassonografia, ou logo após o nascimento devido à manifestação de seus principais fenótipos, tais como, características físicas faciais, a braquicefalia (diâmetro fronto-occipital bastante reduzido), fissuras nas pálpebras inclinadas superiormente, pregas epicânticas (pregas de pele que cobrem os cantos interiores das pálpebras), base do nariz chata, face com diminuição acentuada na atividade de formação de tecidos em sua porção medial e sua língua é hipotônica e levemente deslocada para frente, clinodactilia (deformação) do quinto dedo das mãos, articulações mais fragilizadas e com hipermobilidade, alterações motoras e no sistema endócrino (principalmente relacionados à tireóide), extrema sonolência, geralmente apresentam baixa estatura, hipotonia muscular generalizada, occipital achatado, pescoço curto e grosso, prega única na palma das mãos, andar característico causado pela anteversão pélvica e pela larga base de apoio com os pés voltados para fora, joelhos genovaros (voltados para fora) e comprometimento na capacidade intelectual (TRINDADE; NASCIMENTO, 2016). Importante valer-se da influência da idade reprodutiva da mãe, considerada um dos principais fatores de risco para a origem de trissomias cromossômicas, sendo que, quanto mais avançada a idade, maior será o risco, principalmente acima dos 35 anos de idade (PAIVA et al., 2018).

No que se refere à inclusão escolar, Ferreira e Vicente (2019) pontuam que o processo inclusivo tem caminhado lentamente no Brasil, pois este apresenta variantes de acordo com cada região, mesmo a lei garantindo acesso e permanência as escolas. Deste modo, é importante salientar que muitos pais encontram dificuldades em inserir seu filho com Síndrome de Down no sistema educacional, devido aos medos que carregam consigo, em decorrência de um conjunto de fatores contextuais, oriundos da incipiência de recursos e falta de preparo adequado para que a inclusão aconteça de fato. $\mathrm{A}$ título de exemplo, é possível citar os professores, os quais encontram vários obstáculos em sala de aula, como a flexibilização de currículo, isto é, propor atividades adaptadas específicas às 
necessidades desse público e, ainda, a falta de auxílio e recursos pedagógicos e tecnológicos. Cabe mencionar que se faz necessário o suporte e orientações de equipes interdisciplinares especializadas, composta por médicos, psicólogos, fonoaudiólogos, terapeutas ocupacionais (entre outros), com relação aos pais e aos profissionais envolvidos no ambiente escolar. Somente com um trabalho em equipe e esforço coletivo se torna possível promover a inclusão das pessoas com deficiência na sociedade, sobretudo, na Educação.

Nesse sentido, autores como Vitto-Junior e Lima (2011) corroboram ao afirmarem que é necessário a interação constante entre pais, professores e demais profissionais para atender às necessidades destes educandos, objetivando melhorar seu processo de desenvolvimento e aprendizagem e assim, ajudando-os a expandir seus horizontes e potencialidades. A família deve assumir um papel ativo e colaborativo, concedendo o suporte integral ao aluno.

Levando em consideração os pressupostos supracitados, $\mathrm{o}$ presente ensaio teórico se fundamentou na seguinte pergunta de pesquisa: considerando a importância da relação família-escola para o processo inclusivo, de que forma a aceitação dos pais interfere no desenvolvimento e aprendizagem de seus filhos com Síndrome de Down?

Nessa perspectiva, o artigo teve como principal objetivo explorar a literatura científica nacional acerca dos desafios encontrados por pais, familiares e por professores no processo de inclusão das crianças com Síndrome de Down. Em específico, buscou-se propor discussões sobre a importância da conscientização e colaboração da comunidade para a mudança do paradigma da inclusão, que ainda encontra inúmeros entraves e limitações.

Inicialmente, será apresentada breve conceituação sobre Síndrome de Down e a influência da concepção e aceitação dos pais com relação às deficiências, para o processo de inclusão. Em seguida, será discutido sobre a influência da família na socialização das crianças com deficiência. Por fim, será refletido sobre o processo de inclusão das pessoas com deficiência. Este estudo foi realizado a partir de uma revisão bibliográfica (GIL, 2012), para o qual foram selecionados livros, trabalhos acadêmicos e artigos científicos relacionados à temática em questão.

\section{A concepção dos pais acerca da Síndrome de Down e a importância da aceitação da deficiência para a inclusão}

Quando os casais planejam ter filhos e/ou descobrem que irão ter um bebê, os mesmos, automaticamente, criam expectativas e planejamentos sobre o futuro da criança. Esse fenômeno se intensifica ainda mais quando se começa a imaginar o sexo do bebê: - "se for menina vai fazer balé"; "se for menino vai jogar futebol igual ao pai" (FRANCO, 2017).

Segundo Dantas et al. (2019), o nascimento de uma criança com deficiência pode gerar mudanças em toda a estrutura familiar, como rotinas, horas de sono, horários de lazer, exaustão física e mental causada pela sobrecarga do cuidado, entre outros. Desde o conhecimento da gestação, é comum que os pais idealizem um bebê saudável, em termos de características físicas e emocionais, planejem o futuro e detalhes da vida escolar.

Todavia, todo esse sonho e planejamento mudam completamente quando o médico informa que o filho será uma Pessoa com Deficiência ( $P C D)$, especificamente, nos casos de Síndrome de Down. Segundo Garcia e Paz (2020), Pessoa com Deficiência se refere aos indivíduos que possuem algum tipo de limitação permanente (deficiência visual, auditiva, física ou intelectual). Essa nomenclatura foi adotada a partir da Convenção sobre os Direitos da Pessoa com Deficiência das Nações Unidas, em 2006.

Varella (2019) explica que a Síndrome de Down é uma alteração genética causada por erro na divisão celular. As pessoas com Síndrome de Down ou trissomia do cromossomo 21, têm 47 cromossomos em suas células, em vez de 46 , como no desenvolvimento típico. Os pais, geralmente, não estão preparados para este tipo de experiência, que envolvem frustrações, incertezas e, muitas vezes, sensação de impotência, tornando mais difícil ainda a compreensão e aceitação dos fatos. Após o diagnóstico (de qualquer deficiência e/ou síndrome), os pais passam a sentir culpa pela condição do filho. Para a aceitação e a adaptação dos pais, deve-se considerar o tempo necessário para adquirir informações sobre o quadro, e, assim, enfrentar os múltiplos sentimentos existentes (PAPALIA; FELDMAN, 2013).

De acordo com Andrade (2015), os genitores apresentam dificuldades em aceitar a Síndrome de Down e integrar a criança ao grupo familiar. Ao tentarem elaborar os sentimentos 
vivenciados por eles, bem como se adaptarem a esse contexto, os mesmos podem ficar vulneráveis a altos níveis de estresse e transtornos mentais. É importante ressaltar, que esse momento para os pais pode ter consequências positivas ou negativas na vida da criança, para propiciar, ou não, o vínculo afetivo com seu filho.

Segundo Peñuelas (2018), os pais de crianças com Síndrome de Down fazem de tudo para que seus filhos se desenvolvam e cresçam. Porém, em muitos casos, apresentam medos e dificuldades em inserir a criança no convívio social, principalmente na escola. Com isso, tentam poupá-lo de frustrações, apoiando-a à sua maneira ingênua de pensar, assumindo posturas superprotetoras. Deste modo, restringem o curso natural do desejo de desenvolvimento, mantendo o indivíduo infantilizado, imaturo e dependente, sendo que esta independência para as pessoas com Síndrome de Down é relativa, mesmo que necessitem de supervisão em algumas atividades.

Todavia, para Ramos (2015), muitas são as barreiras a serem superadas para garantir a acessibilidade de pessoas com necessidades educacionais especiais às salas de aula e escolas comuns da rede regular de ensino. Para que a inclusão ocorra com sucesso é necessário que a comunidade acredite na competência das escolas em atender às necessidades de todos os estudantes. Os pais devem ter confiança na capacidade das instituições escolares educarem alunos em conjunto, independentemente de suas especificidades. Nesse sentido, é de suma importância a promoção de programas que visem amparar a família e fortalecer o vínculo famíliaescola.

[...] a escola deve ter o cuidado de desenvolver estratégias que atraiam a participação dos pais em sua organização e tomada de decisões. Dessa forma, poderá contribuir para que haja uma relação harmoniosa com a família, relação esta que precisa estar pautada no respeito mútuo. O diálogo precisa ser constante para se resolverem os conflitos da melhor maneira, conhecer melhor o aluno, comparar e analisar seu comportamento em casa e na sala de aula buscando

juntas estratégias que poderão ajudá-lo a desenvolver ao máximo suas potencialidades. A escola precisa estar pronta para receber as famílias e auxiliá-las em suas dificuldades com a criança com Síndrome de Down através de reuniões periódicas, palestras ou conversas que tenham caráter informativo, de aconselhamento socialização 2015, p.21).

Desta forma, o suporte de profissionais torna-se indispensável. São eles que irão apoiar, fornecer informações e orientações, designar alternativas que a família pode ter para auxiliar no desenvolvimento da criança, a qual, desde o nascimento, carrega estigmas e preconceito. Cabem, também, aos psiquiatras e psicólogos auxiliar as mães e pais durante o processo de aceitação e enfrentamento da situação, pois estes podem ficar vulneráveis e desenvolverem quadros de transtornos mentais e comportamentais, assumindo condutas desadaptativas que podem se tornar fatores de risco para suas vidas ou, até mesmo, às crianças (PAPALIA; FELDMAN, 2013; BOGO; CAGNINI; RADUENZ, 2014).

O suporte concedido pela equipe interdisciplinar visa fornecer informações com embasamento científico, para que a família permita que a criança tenha as condições necessárias para o desenvolvimento psicomotor. Com os avanços da ciência, percebe-se o aumento de oportunidades de desenvolvimento pessoal e profissional das pessoas com Síndrome de Down, nas diversas áreas do conhecimento. Porém, para que isso aconteça, é necessário que os pais, a família e uma equipe profissional auxilie a criança desde a Educação Infantil.

[...] as crianças com
qualquer tipo de
deficiência,
independentemente de
suas condições físicas,
sensoriais, cognitivas ou
emocionais, são crianças
que têm as mesmas
necessidades básicas de
afeto, cuidado e proteção,


e os mesmos desejos e sentimentos das outras crianças. Elas têm a possibilidade de conviver, interagir, trocar, aprender, brincar e serem felizes, embora, algumas vezes, de forma diferente. Essa forma diferente se ser e de agir é que as tornam seres únicos e singulares. Elas devem ser olhadas não como defeito, mas como pessoas com possibilidades diferentes, com algumas dificuldades, que, muitas vezes, tornam-se desafios com os quais podemos aprender e crescer, como pessoas e profissionais que buscam ajudar o outro (ANHÃO, PFEIFER, SANTOS, 2010, p.43).

Há algumas estratégias que podem ser utilizadas para que as crianças com Síndrome de Down desenvolvam repertórios comportamentais e habilidades sociais. As instruções devem se apresentar de forma clara e objetiva, com linguagem corporal para reforço e deve-se distinguir o que pode ou não ser feito, estimulando comportamentos adaptativos (COLNAGO, 2000; SOUSA, 2017). Para Santos (2018) respeitar os limites e as particularidades de aprendizado de cada aluno com deficiência é o primeiro de muitos passos para a inclusão. É preciso que o professor esteja disposto e compreenda a diversidade presente na sala de aula.

Sendo assim, o princípio orientador do atendimento às pessoas com deficiência não deve ser dada às limitações, mas às habilidades que essas possuem, na capacidade de desenvolvimento e mudança do ser humano (BEZERRA, 2015). De acordo com Santos (2014), uma das coisas que se pode notar na relação dos pais para com seus filhos é o apego, que faz com que o relacionamento seja um repertório de atos instintivos, ou seja, o pensamento de que quanto mais próximo estiver do filho, mais protegido este estará. Em contradição a este assunto, também existem pais que, abertamente, rejeitam seus filhos, deixam bem claro que não os amam ou não os querem devido às suas condições. Em alguns casos, essa rejeição ocorre devido ao medo, preconceito e falta de informação. Ao deparar-se com a deficiência, a família desesperase por crenças de que a síndrome se resume a obstáculos sem soluções.

$\mathrm{O}$ quadro familiar e afetividade destes para com a criança com Síndrome de Down é essencial para o desenvolvimento biopsicossocial do indivíduo, pois a família é o primeiro ambiente da criança. Nessas premissas, a família, a escola e a equipe interdisciplinar podem trabalhar juntos em direção às soluções mútuas para promover maior qualidade de vida e estratégias adaptativas para o desenvolvimento e inclusão escolar da criança com Síndrome de Down. Essa união contribui para todo o processo de integração, inserção, manutenção e progresso da criança com deficiência na família e sociedade (PEREIRA, 2012).

\section{A influência da família na socialização de crianças com Síndrome de Down}

O meio familiar é o primeiro contexto onde as pessoas socializam. Ao nascer, o ambiente da criança é restrito e se limita apenas a sua casa. O tipo de relação estabelecido com esse meio está condicionado à mediação de terceiros, ou seja, a família proporciona condições para que a criança explore o ambiente e estabeleça uma relação com o mesmo. Com o passar do tempo, a criança começa a ser apresentada a outros ambientes, ampliando seu contato com outras pessoas. $O$ ambiente acolhedor da família possibilita para a criança potencializar suas qualidades (SILVA; NASCIMENTO; SOARES, 2018).

A família é vista como referência, ou seja, concede modelos para que as crianças convivam em sociedade, pois todos os valores culturais, sociais e costumes são transmitidos neste grupo. No entanto, nem todas as famílias aceitam um novo membro. Nos casos de PDC, principalmente as famílias de baixa renda, podem apresentar dificuldade nessa aceitação devido a pouca informação e o baixo acesso à serviços especializados, apesar de a saúde pública ser gratuita. Sobre essa questão, Nunes, Costa e Guimarães (2013) ressaltam que as famílias que aceitam com mais facilidade seus membros com deficiência são as que possuem alto poder aquisitivo, o que possibilita o acompanhamento interdisciplinar com profissionais de diferentes seguimentos, os quais são essenciais para atender às necessidades dos PCD, em relação à inclusão social e escolar. 
Para Pinto e Morgado (2012), os pais desempenham um papel muito importante no desenvolvimento das crianças, haja vista que estes exercem influência sobre as atitudes e concepções que seus filhos apresentam. Deste modo, atitudes positivas demonstradas pelos pais influenciam a forma como as crianças irão interagir umas com as outras, sendo este um fator determinante para a socialização.

Dificuldades no desenvolvimento cognitivo e manutenção de relacionamentos interpessoais constituem fatores associados ao comportamento, corroborando para a incipiência de habilidades sociais. Segundo Mota (2013), a qualidade das relações familiares é um fator determinante no comportamento social das crianças. Os comportamentos sociais mais equilibrados correspondem ao estilo parental responsável, em que os pais são afetuosos e hábeis em confrontar a criança com as suas reações emocionais. Por outro lado, crianças com pais muito autoritários ou com modos ríspidos e punitivos apresentam mais dificuldade em relacionar-se com os demais. Essas punições físicas fundamentadas em uma educação coerciva podem promover um estilo agressivo e atitudes hostis na criança. Deste maneira, as expectativas dos pais influenciam a competência social da criança. No que se refere ao comportamento, as crianças com Síndrome de Down podem apresentar maiores dificuldades, sobretudo ao nível da atenção e maturidade. Portanto, a família assume um papel importante, pois é no meio familiar que se iniciam as interações e as referências sociais.

Rodriguez e Carneiro (2012) compreendem que, para o desenvolvimento infantil na dimensão social de crianças com Síndrome de Down, faz-se necessário proporcionar espaços onde o adulto se torna o mediador ou facilitador, guiando as relações entre as crianças. O auxílio profissional em caráter de orientação facilita a socialização, sendo que esta parceria entre profissionais e familiares ajuda no desenvolvimento e na capacidade de intervir assertivamente em determinadas situações, para que se possa produzir melhores resultados na construção de repertórios comportamentais referentes às habilidades sociais. Em suma, quando a família e todos os envolvidos recebem informações sobre como intervir nessa mediação entre as crianças, cria-se uma linguagem comum para a construção de um relacionamento colaborativo entre os familiares e a criança com Síndrome de Down. Assim, proporciona-se uma interação que oportuniza espaços de experiências e socialização, ampliando o desenvolvimento de capacidades e habilidades, as quais permitem que a criança com a Síndrome ou qualquer outra deficiência, torne-se independente e autêntico em seus espaços de convívio social.

Nessa direção, ressalta-se a necessidade da ajuda de profissionais e de movimentos que contribuam com a inclusão das PCD em espaços públicos para que, assim, todos possam ser tratados com equidade. Enfatiza-se também, a questão de a família enfrentar uma série de desafios, uma vez que ela também sofre com a pressão social (ANHÃO; PFEIFER; SANTOS, 2010).

A falta de informação e de apoio especializado pode interferir na qualidade de vida tanto dos pais quanto da criança com deficiência. Sobre isso, Ferreira et al. (2019) explica que gradualmente a insegurança dos pais pode ser superada mediante conscientização, enfrentado a realidade e os desafios diários, ou seja, adaptando-se.

Por fim, Ávila et al. (2017) salienta que o apoio especializado aos pais deve incluir informações relevantes às suas preocupações, tais como o detalhamento sobre a deficiência do filho e sobre suas características físicas e mentais, para que assim, os genitores possam proceder da melhor forma em relação ao desempenho desejado. Além disso, as orientações podem ser concedidas em vários momentos do desenvolvimento da criança, desde o diagnóstico pré-natal e principalmente, no ingresso à escola.

\section{O processo de inclusão de Pessoas com Deficiência: desafios e perspectivas}

$\mathrm{Na}$ atualidade, por diversos motivos inclusive os históricos - é que se ouve falar em inclusão. Em toda história, o início da luta por uma sociedade inclusiva se deu, prioritariamente, em relação a uma minoria, que por ação e crença fortemente ligada à ideais religiosos, todos que nasciam com alguma característica física ou mental diferente do padrão imposto na época, eram abandonados, excluídos e segregados. As pessoas com deficiência eram vistas como ação "maligna e pecado" e eram frequentemente tidas como possuídas pelo "demônio" e queimadas na fogueira da Santa Inquisição. O povo da época, via o nascimento de pessoas com deficiência como "castigo" de Deus. As crianças eram separadas de suas famílias, ridicularizadas e se 
tornavam focos de diversão dos mais ricos (CORRENT, 2016).

Logo veio o período de segregação das pessoas com deficiência, os quais estes indivíduos passaram a serem alojados em hospitais, asilos e instituições mantidas pela Igreja. Desde os primeiros registros históricos, percebe-se os estigmas direcionados às deficiências, marginalizando e privando essas pessoas de liberdade. Infelizmente, ainda, para alguns indivíduos, é mais fácil prestar atenção aos impedimentos e às aparências do que aos potenciais e capacidades das pessoas com deficiência (FERNANDES, 2011).

Porém, com os avanços da ciência e tecnologia, mudanças começaram a se mostrar crescentes e significativas, no que se referem às questões sociais, políticas e legais à inclusão de PCD. Mazzotta e D'Antino (2011) afirmam que, na realidade, ainda se exige uma mudança na estrutura social vigente, no sentido de organizar uma sociedade que atenda aos interesses de todas as pessoas, indiscriminadamente. Dessa forma, lutar a favor da inclusão social deve ser responsabilidade de cada um e de todos.

A luta da inclusão constitui-se de um conjunto de ações para combater a exclusão provocadas pelas diferenças de classe sociais, educação, idade, deficiência, gênero e etnia. Inclusão social é oferecer oportunidades iguais de acesso a bens e serviços a todos, destacando as pessoas com deficiências. Assim, os termos "integração" e "inclusão" representam movimentos em defesa dos interesses das pessoas que apresentam alguma deficiência (BERGAMO, 2010).

A inclusão é um movimento educacional, mas também social e político que vem defender o direito de todos os indivíduos participarem, de uma formal consciente e responsável, na sociedade de que fazem parte, e de serem aceites e respeitados naquilo que os diferencia dos outros. No contexto educacional, vem, também, defender o direito de todos os alunos desenvolverem e concretizarem as suas potencialidades, bem como de apropriarem as competências que lhes permitam exercer o seu direito de cidadania, através de uma educação de qualidade, que foi talhada tendo em conta as suas necessidades, interesses e características (FREIRE, 2008, p.5-20).

De acordo com Yaegashi et al. (2021), a inclusão de pessoas com deficiência na educação apresenta um avanço notável na legislação Brasil, sendo essa temática o foco de inúmeras discussões científicas, políticas e sociais. A respeito disso, cita-se que no II Congresso Brasileiro e I Encontro Latino Americano em Brasília sobre Síndrome de Down aconteceram palestras sobre educação inclusiva ministradas por especialistas, e, a cada contato com as pesquisas e informações, identificou-se a necessidade de diferenciar os conceitos "integração" e 'inclusão" de PCD.

Existem postulados legais, como a Declaração Mundial sobre Educação para Todos (Unesco, 1990), aprovada pela Conferência Mundial sobre Educação para Todos, realizada em Jomtiem, na Tailândia, no ano de 1990; a Declaração de Salamanca (Unesco, 1994), firmada na Espanha em 1994; a Constituição Federal de 1988, art. 208, inciso III; o Plano Decenal de Educação para Todos, 1993-2003 (MEC, 1993); a Lei de Diretrizes e Bases da Educação Nacional 9.694/96 (Capítulo V); e os Parâmetros Curriculares Nacionais (MEC, 1999). Esses documentos defendem e asseguram 0 direito de todos à educação, segundo esses documentos, todas as crianças devem ser acolhidas pela escola, independentemente de suas condições físicas, intelectuais, sociais e emocionais (RODRIGUES, 2013, p.3787). 
Segundo Ferreira (2009), a inclusão se estabeleceu com a Lei de Diretrizes de Bases da Educação Nacional (BRASIL, 1996) e com a Convenção da Guatemala, de 2001 (BRASIL, 2001), as quais afirmaram que manter crianças com algum tipo de deficiência fora do ensino regular é considerado exclusão e crime. Todavia, o movimento pela inclusão ainda se encontra em desenvolvimento, caminhando lentamente no país, em pleno século XXI. Cabe destacar a importância da Lei Brasileira de Inclusão da Pessoa com Deficiência, denominado Estatuto da Pessoa com Deficiência, no 13.146/2015 (BRASIL, 2015), a qual foi aprovada em 6 de julho de 2015 e trouxe o princípio da dignidade da pessoa humana como diretriz básica, buscando condições de igualdade, o exercício dos direitos e das liberdades fundamentais para a pessoa com deficiência, visando à sua inclusão social e cidadania. Em seu Art. 2으, define-se Pessoa com Deficiência aquela que tem impedimento de longo prazo de natureza física, intelectual ou sensorial, o qual, em interação com uma ou mais barreiras, pode obstruir sua participação plena e efetiva na sociedade em igualdade de condições com as demais pessoas. "A Lei 13.146, de 6 de julho de 2015 , vigente nos dias atuais, deixa claro que a escola não tem o direito de negar a matrícula e muito menos cobrar taxas extras da pessoa com SD, podendo ser decretado a prisão da pessoa responsável por essa negação" (MINETTO et al., 2018).

Em contrapartida, a Lei de Inclusão é um importante passo para garantir legitimidade à luta, mas sua implementação, na prática, depende da conscientização das autoridades e da população em geral sobre a necessidade e importância desses feitos. Leite e Mont'Alverne (2021) apontam que a inclusão vem acontecendo de modo gradativo, sendo necessário percorrer um longo processo para que a inclusão para todos possa se tornar efetiva como apresentado nas leis que a garantem. "[...]inclusão ainda é algo não acessível a todos no Brasil, necessitando assim de maiores investimentos e uma maior efetivação daspolíticas no processo inclusivo" (LEITE; MONT'ALVERNE, 2021, p.7).

Entretanto, percebe-se que a sociedade começou a despertar para esse assunto, e, em decorrência de maior participação coletiva, tem sido criado mecanismos com o objetivo de facilitar a inclusão social, profissional e educacional de pessoas com deficiência. Em
2003, o Ministério da Educação implementou o "Programa Educação Inclusiva: direito à diversidade", que tem como objetivo promover o processo de formação de gestores e educadores nos municípios brasileiros para a garantia do direito de acesso de todos à escolarização, à oferta do atendimento educacional especializado e à garantia da acessibilidade, para a transformação do ensino (BRASIL, 2016). Em 2004, o Ministério Público Federal publica o documento "O Acesso de Estudantes com Deficiência às Escolas e Classes Comuns da Rede Regular", com o objetivo de disseminar os conceitos e diretrizes mundiais para a inclusão, reafirmando o direito $e$ os benefícios da escolarização de estudantes com e sem deficiência para os alunos do ensino regular (BRASIL, 2016).

A Convenção sobre os Direitos das Pessoas com Deficiência, aprovada pela ONU e ratificada com força de Emenda Constitucional, por meio do Decreto Legislativo $n^{\circ} 186 / 2008$ e do Decreto Executivo n6949/2009, em seu artigo $n=24$, estabeleceu que os Estados Partes devem assegurar um sistema de Educação Inclusiva em todos os níveis de ensino (SOUZA; MIRANDA, 2021).

De acordo com Yaegashi et al. (2021), houve grandes movimentos em em prol da inclusão, assim como um avanço notável na legislação, e isso ocorreu com muita força no Brasil. Porém, isso ainda não se mostra suficiente. Mesmo com o grande avanço já obtido, ainda há muito o que melhorar em termos de tratamento e educação da PCD. $O$ autor salienta que a sociedade precisa romper paradigmas, para que de fato coloque em prática os princípios de igualdade, liberdade e fraternidade. Ou seja, a inclusão é a aceitação da diversidade, e assim, faz-se necessário a ruptura dos antigos pilares que antes sustentavam uma estrutura de preconceitos e indiferença.

No contexto da Síndrome de Down, a sociedade inclusiva não verá essa condição como doença, anormalidade ou inferioridade. Para que ocorra a inclusão, faz-se necessário que a sociedade e as instituições escolares estejam preparadas para adaptar atividades pedagógicas e sociais, espaços físicos, contribuindo para o desenvolvimento da PCD. Em uma perspectiva de Educação Inclusiva, é proposta que as crianças com deficiência sejam educadas na rede regular de ensino, para favorecer seu desenvolvimento biopsicossocial. A inclusão escolar deve acontecer 
desde a Educação Infantil. O intuito é preparar todas as crianças para que aprendam a respeitar e a conviver com as diferenças de cada indivíduo a fim de que seja possível a criação de uma sociedade mais justa, inclusiva e que respeite a diversidade. Todos da comunidade escolar e envolvidos no tratamento e/ou acompanhamento do aluno devem atuar em conjunto, diretores, coordenadores, inspetores, professores e de profissionais da saúde, como médicos, psicólogos, fisioterapeutas e fonoaudiólogos, por exemplo. (SILVA; NASCIMENTO; SOARES, 2018).

\section{CONCLUSÕES}

A partir da realização da pesquisa, foi possível identificar primeiramente as principais demandas emocionais e desafios vivenciados pelos pais, com relação ao processo de aceitação de um filho com deficiência. Quanto às contribuições, foi observado que é de suma importância o suporte concedido pela equipe interdisciplinar que atende à criança, pois, a falta de orientação e informações para a família lidar com o quadro, pode se apresentar como um agravante para o enfrentamento e demais etapas no tratamento e inclusão da criança com deficiência, especialmente nos casos de Síndrome de Down.

Quanto ao fator socialização, a família é o principal agente, por se tratar do primeiro vínculo da criança em determinado grupo, onde se adquire valores, costumes, comportamentos e regras de convivência. Contudo, sentimentos de medo sobre a capacidade da criança em lidar com as outras pessoas e a crença de que esta é dependente (ou seja, não é capaz de tomar decisões, conviver com diferentes pessoas sem sua supervisão), podem dificultar o desenvolvimento psicossocial, bem como, corroborar para a existência de preconceitos na própria família do indivíduo com Síndrome de Down.

Outra temática discutida foi o reflexo da bagagem histórica da inclusão até os dias atuais, uma vez que, infelizmente, em pleno século XXI, ainda se tem crenças preconceituosas e estigmatizantes a respeito das pessoas com deficiência. Ainda existem muitas pessoas que acreditam que estes devem ficar apenas em instituições especializadas, tratam-no como um ser humano incomum. Esse problema, tão antigo quanto o homem, define-se pela falta de informações, oportunidades, injustiça social, preconceitos e inabilidade da sociedade em lidar com a diversidade.

Apesar de ser um processo lento e vagaroso, a inclusão social e educacional tem evoluído com o passar dos anos, a partir do surgimento de políticas que garantem o direito de conviver em sociedade, trabalhar e frequentar escolas regulares. A inclusão designa o ato de fazer parte de algo e, neste caso, todas as PCD têm o direito de exercerem suas cidadanias e papéis sociais.

É notório a necessidade da criação de novas práticas pedagógicas para proporcionar as condições ambientais adequadas para a aprendizagem e desenvolvimento socioafetivo e cognitivo das crianças com Síndrome de Down e das Pessoas com Deficiência. Todavia, cabe mencionar a importância da sociedade ser mais atuante, que os professores estejam engajados em programas de educação continuada e que a família participe ativamento neste processo de inclusão, 0 qual se faz mediante $o$ acompanhamento e orientação de profissionais da saúde para a melhor qualidade de vida e bemestar do aluno.

$\mathrm{Na}$ perspectiva de elucidar as reflexões acerca da temática, sugere-se que pesquisas futuras realizem revisões bibliográficas adicionando outras bases de dados, contemplando outros conjuntos de palavraschave e inclusive, palavras-chave em outros idiomas, além da língua portuguesa. Compreender quais são os possíveis recursos pedagógicos e práticas inclusivas para trabalhar com crianças e adolescentes com deficiência e mais especificamente, com Síndrome de Down, são alguns dos direcionamentos que podem corroborar para a comunidade acadêmica e escolar.

\section{REFERÊNCIAS}

ANDRADE, F. M. R. R. O luto do filho idealizado: pais da criança com sindorme de down. 2015. Dissertação (Mestrado) -. Instituto Universitário Ciências Psicológicas, Sociais e da Vida, Lisboa, Portugal, $2015 . \quad$ Disponível em: https://core.ac.uk/download/pdf/70655422.pdf. Acesso em: 24 out. 2021.

ANHÃO, P. P. G.; PFEIFER, L. I.; SANTOS, J. L. Interação social de crianças com síndrome de Down na educação infantil. Revista Brasileira de Educação Especial, Marília, v. 16, n. 1, p. 31-46 $2010 . \quad$ Disponível em: 
http://www.scielo.br/scielo.php?script=sci_arttex t\&pid=S1413-65382010000100004. Acesso em: 19 mar. 2021. https://doi.org/10.1590/S1413$\underline{65382010000100004}$

ÁVILA, R. F. et al. Síndrome de Down: o impacto do diagnóstico sob a ótica dos pais em um projeto de extensão. Revista Fragmentos de Cultura-Revista Interdisciplinar de Ciências Humanas, v. 27, n. 1, p. 124-133, 2017. Disponível em: http://revistas.pucgoias.edu.br/index.php/fragm entos/article/view/5448. Acesso em: 25 out. 2021. https://doi.org/10.18224/frag.v27i1.5448

BERGAMO, R. B. Educação especial: pesquisa e prática. Curitiba: Ibpex, 2010.

BEZERRA, M. F.; MARTINS, P. C. R. A concepção de deficiência intelectual ao longo da história. Interfaces da Educação, v. 1, n. 3, p. 7383, 2015.Disponível em: https://periodicosonline.uems.br/index.php/inter faces/article/view/617. Acesso em: 02 nov. 2021. https://doi.org/10.26514/inter.v1i3.617

BOGO, M. L. F.; CAGNINI, Z. V. S.; RADUENZ, M. Momento do diagnóstico de deficiência: sentimentos e modificações na vida dos pais, $2014 . \quad$ Disponível em: https://psicologado.com.br/psicologiageral/desenvolvimento-humano/momento-dodiagnostico-de-deficiencia-sentimentos-emodificacoes-na-vida-dos-pais. Acesso em: 20 maio 2021.

BRASIL. Ministério da Educação. Consolidação da Inclusão Escolar no Brasil - 2003 a 2016. Brasília: MEC, 2016.

BRASIL. Ministério da Educação. Decreto no 3.956, de 8 de outubro de 2001. Promulga a Convenção Interamericana para a Eliminação de Todas as Formas de Discriminação contra as Pessoas Portadoras de Deficiência. Guatemala, $2001 . \quad$ Disponível em: http://portal.mec.gov.br/seesp/arquivos/pdf/gua temala.pdf. Acesso em: 31 out. 2021.

BRASIL. Ministério da Educação. Lei 13.146/2015 de 06 de julho de 2015. Institui a Lei Brasileira de Inclusão da Pessoa com Deficiência (Estatuto da Pessoa com Deficiência). Disponível em : http://www.planalto.gov.br/ccivil_03/_Ato2015-
2018/2015/Lei/L13146.htm. Acesso em: 31 out. de 2021.

BRASIL. Lei de Diretrizes e Bases da Educação Nacional, LDB. 9394/1996.

COELHO, C. A síndrome de Down. Psicologia.pt. p. 1-14, 2016. Disponível em: https://www.psicologia.pt/artigos/textos/A0963. pdf. Acesso em: 27 mar. 2021.

COLNAGO, N. A. S. Orientação para pais de crianças com síndrome de down: elaborando e testando um programa de intervenção. 2000. Tese (Doutorado) -. Universidade de São Paulo, Ribeirão Preto, 2000. Disponível em: https://www.teses.usp.br/teses/disponiveis/59/5 9137/tde-19112008-

214630/publico/Teseneucideia.pdf. Acesso em: 21 mar. 2021.

CORRENT, N. Da antiguidade a contemporaneidade: a deficiência e suas concepções. Revista Científica Semana Acadêmica. Fortaleza, ano MMXVI, n. 000089, $2016 . \quad$ Disponível em: https://semanaacademica.org.br/system/files/art igos/nikolas_corrent_educacao_especial.pdf.

Acesso em: 25 out. 2021.

DANTAS, K. O. et al. Repercussões do nascimento e do cuidado de crianças com deficiência múltipla na família: uma metassíntese qualitativa. Cadernos de Saúde Pública, v. 35, $2019 . \quad$ Disponível em: https://www.scielo.br/j/csp/a/scrMsWn7YC5wxS bVCQxWsRK/?format=html\&lang=pt. Acesso em: 27 out. 2021. https://doi.org/10.1590/0102$\underline{311 \times 00157918}$

FEDERAÇÃO DAS ASSOCIAÇÕES DE SÍNDROME DE DOWN. Síndrome de Down. 2019. Disponível em: http://federacaodown.org.br/sindrome-dedown/. Acesso em: 18 out. 2021.

FERNANDES, S. Fundamentos para Educação Especial. 2.ed. Curitiba: Ibpex, 2011.

FERREIRA, M. et al. Repercussões do Diagnóstico de Síndrome de Down na Perspectiva Paterna. Psicologia: Ciência e Profissão, v. 39, $2019 . \quad$ Disponível em: https://www.scielo.br/j/pcp/a/bN73Yh7Q4xKKPd 
xf95CdfVL/?lang=pt. Acesso em: 07 ago. 2021. https://doi.org/10.1590/1982-3703003181365

FERREIRA, M. F. M.; VICENTI, T. O processo de inclusão do aluno deficiente no ensino regular público na última década no Brasil. Atitude, $p$. 201628, 2019. Disponível em: https://antigo.faculdadedombosco.net/wpcontent/uploads/2016/05/RevistaAtitude2016.pd f\#page $=28$. Acesso em: 18 out. 2021.

FRANCO, V. Idealização e re-idealização no desenvolvimento dos pais e mães das crianças com deficiência. Repositório da Universidade de Évora, Portugal, 2017. Disponível em: https://dspace.uevora.pt/rdpc/handle/10174/21 995. Acesso em: 24 out. 2021.

FREIRE, S. Um olhar sobre a inclusão. Revista de Educação, p. 5-20, 2008. Disponível em: https://repositorio.ul.pt/handle/10451/5299.

Acesso em: 7 ago. 2021.

GARCIA, P.; PAZ, F. J. Educação Inclusiva no ambiente universitário. Anais do Salão Internacional de Ensino, Pesquisa e Extensão, v. 10, n. 2, 2020. Disponível em: https://periodicos.unipampa.edu.br/index.php/SI EPE/article/view/101076. Acesso em: 19 mar. 2021.

GIL, A. C. Como elaborar projetos de pesquisa. 4. ed. São Paulo: Atlas, 2012.

IBGE - INSTITUTO BRASILEIRO DE GEOGRAFIA E ESTATÍSTICA - Censo Pessoas com Deficiência, $2010 . \quad$ Disponível em: https://www.ibge.gov.br/apps/snig/v1/?loc=0\&c at $=-1,-2,-3,128 \&$ ind $=4643$ Acesso em: 03 mar. 2021.

LEITE, M. M. F.; MONT'ALVERNE, C. R. Inclusão: um caminho que precisa ser percorrido. Revista Ibero-Americana de Humanidades, Ciências e Educação, v. 7, n. 5, p. 683-695, 2021. Disponível em:

https://periodicorease.pro.br/rease/article/view/ 1227. Acesso em: 29 out. 2021. https://doi.org/10.51891/rease.v7i5.1227

LONDERO, A. D. et al. Adaptação parental ao filho com deficiência: revisão sistemática da literatura. Interação em Psicologia, v. 25, n. 2, $2021 . \quad$ Disponível https://revistas.ufpr.br/psicologia/article/view/6
0759. Acesso em: 16 out. 2021. https://doi.org/10.5380/riep.v25i2.60759

MAZZOTTA, M. J. S.; D’ANTINO, M. E. F. Inclusão social de pessoas com deficiências e necessidades especiais: cultura, educação e lazer. Saúde e sociedade. v. 20, n. 2, p. 377-389, 2011. Disponível em: https://www.scielo.br/scielo.php?script=sci_artte xt\&pid=S0104-12902011000200010. Acesso em: 27 mar. 2021. https://doi.org/10.1590/S0104$\underline{12902011000200010}$

MIERLO, A. I. V. et al. Avaliação bioquímica e hematológica em indivíduos com deficiência intelectual associada ou não à síndrome de Down. Jornal Brasileiro de Patologia e Medicina Laboratorial, v. 54, p. 9-13, 2018. Disponível em: https://www.scielo.br/j/jbpml/a/4BJ47DjwWbfYZ dnQfpFDM6d/abstract/?format=html\&lang=pt.

Acesso em: 24 out. 2021.

MINETTO, M. F. et al. A Escolha da Escola para Filhos com síndrome de Down. Da investigação às práticas, v. 8, n. 1, p. 62-78, 2018. Disponível em:

https://repositorio.ipl.pt/handle/10400.21/9848. . Acesso em: 25 out. 2021.

MOTA, N. G. A relação entre pares, no ensino básico, com alunos de necessidades educativas especiais integrados na turma. 2013. Tese (Doutorado) - . Escola Superior de Educação João de Deus, Lisboa, Portugal, 2013. Disponível em: https://comum.rcaap.pt/bitstream/10400.26/408 5/1/NataliaMota.pdf. Acesso em: 05 nov. 2021.

NANTES, E. S. Representações de docentes sobre as sexualidades da pessoa com síndrome de down. 2018. Dissertação (Mestrado) . Universidade Estadual de Maringá, Maringá, $2018 . \quad$ Disponível em: http://www.ppe.uem.br/dissertacoes/2018/2018 \%20-\%20Elaine\%20Nantes.pdf.Acesso em: 25 out. 2021.

NUNES, F. C.; COSTA, J. S.; GUMARÃES, M. T. o papel da família na interação de crianças portadoras da síndrome de Down no meio social. 2013. Disponível em: http://www.profala.com/artsindrome16.htm. Acesso em: 24 maio 2019. 
OMS - ORGANIZAÇÃO MUNDIAL DA SAÚDE. Relatório mundial sobre a deficiência/The World Bank. Traduzido por Lexicus Serviços Linguísticos. São Paulo: SEDPcD, 2012.

PAIVA, C. F. et al. Síndrome de Down: etiologia, características e impactos na família. Interação em Psicologia, São Paulo, v. 6, n. 2, p. 167, 2018. Disponível em:

https://www.educaretransformar.net.br/wpcontent/uploads/2017/03/S\%C3\%8DNDROMEDE-DOWN-E-ETIOLOGIA.pdf. Acesso em: 18 out. 2021.

PAPALIA, D. E.; FELDMAN, R. D. Desenvolvimento Humano. 12. ed. Porto Alegre: Artmed, 2013.

PEÑUELAS, B. G. Como promover a autonomia pessoal do meu filho com síndrome de down. Revista virtual de síndrome de down, n. 201, $2018 . \quad$ Disponível em: https://www.down21.org/revista-virtual/1743revista-virtual-2018/revista-virtual-sindrome-dedown-febrero-2018-n-201/3158-articuloprofesional-como-favorecer-la-autonomiapersonal-de-mi-hijo.html. Acesso em: 20 mar. 2021.

PEREIRA, L. E.R. Percepção de educadores sobre o processo de inclusão em uma unidade municipal de educação infantil. 2012. Trabalho de Conclusão de Curso (Graduação) Universidade

Federal de Minas Gerais, Belo Horizonte, 2012. Disponível em: https://repositorio.ufmg.br/bitstream/1843/VRN S-9NRMLX/1/luzia_acpp_final.pdf. Acesso em: 20 mar. 2021.

PINTO, N.; MORGADO, J. A. M. Atitudes de pais e professores perante a inclusão. In: COLÓQUIO INTERNACIONAL DE PSICOLOGIA E EDUCAÇÃO. 12., 2012, Lisboa, PO. Actas [...] Lisboa: ISPA, 2012, p. 471-491 Disponível em: https://core.ac.uk/download/pdf/70650382.pdf. Acesso em: 07 ago. 2021.

RAMOS, V. M. M. Estratégias de ensino favoráveis ao desenvolvimento do aluno com síndrome de down no Ensino Fundamental $I$. [Monografia]. Universidade de Brasília - UnB, Brasília, 2015. Disponível em: https://bdm.unb.br/handle/10483/15571. Acesso em: 25 out. 2021.
RODRIGUES, M. C. Representações docentes acerca da inclusão de alunos com deficiência visual ao Ensino Regular. In: ENCONTRO DA ASSOCIAÇÃO BRASILEIRA DE PESQUISADORES EM EDUCAÇÃO ESPECIAL, 8., 2013, Londrina. Anais [...]. Londrina: 2013 p. 3780-3795.Disponível em: http://www.uel.br/eventos/congressomultidiscip linar/pages/arquivos/anais/2013/AT01-

2013/AT01-087.pdf. Acesso em: 31 out. 2021

RODRIGUEZ, F. T.; CARNEIRO, T. F. Os bebês com síndrome de Down e seus pais: novas propostas para intervenção. Estud. psicol., Campinas, 29 (suppl. 1), 2012. Disponível em: https://www.scielo.br/scielo.php?pid=S0103166X2012000500019\&script=sci_arttext. Acesso em: 21 mar. 2021. https://doi.org/10.1590/S0103$\underline{166 \times 2012000500019}$

SALES, F. A influência familiar no desenvolvimento das pessoas com deficiência. Revista Eletrônica de Ciências da Educação. Campo Largo, v. 16, n. 1 e 2, abril de 2017. Disponível em: http://www.periodicosibepes.org.br/index.php/r eped/article/view/2360/905. Acesso em: 20 mar. 2021.

SILVA, F. O. D.; NASCIMENTO, H. C.; SOARES, M. $H$. Inclusão escolar para crianças com síndrome de down. Repositório Institucional da Faculdade Doctum da Serra, 2018. Disponível em: https://dspace.doctum.edu.br/handle/12345678 9/1912. Acesso em: 04 ago. 2021.

SANTOS, A. S. Contribuição para adaptação transcultural do instrumento "adaptação e resiliência em famílias de indivíduos com Síndrome de Down" para o português do Brasil. 2014. Dissertação (Mestrado) - Universidade do Porto, Portugal, 2014. Disponível em: https://repositorioaberto.up.pt/bitstream/10216/78592/2/34673.p df. Acesso em: 20 mar. 2021.

SANTOS, M. C. D. Marcos legais da educação infantil inclusiva. Diversa: Educação Inclusiva na Prática,publicado em 15 jul. 2016. Disponível em: https://diversa.org.br/artigos/marcos-legaisda-educacao-infantil-

inclusiva/?gclid=CjOKCQjwutaCBhDfARIsAJHWnH uE6IMihhvGEmcK3svCWFhuGfZwwCbToxKYutjrO 
Xd6BCmRLWXTRsUaAtfmEALw_wcB. Acesso em: 20 mar. 2021.

SANTOS, N. S. S. A inclusão de alunos com deficiência no ensino regular. Revista Docentes, v. 3, n. 7, 2018. Disponível em: https://revistadocentes.seduc.ce.gov.br/index.ph $\mathrm{p} / \mathrm{revistadocentes/article/view/82}$. Acesso em: 05 ago. 2021.

SOUSA, E. M. Políticas Públicas e a Inclusão Social da Síndrome de Down. Revista Científica Multidisciplinar Núcleo do Conhecimento, v. 1, n. 2, p. 987-1050, jul. 2017. Disponível em: https://www.nucleodoconhecimento.com.br/ad ministracao/sindrome-de-down. Acesso em: 19 mar. 2021. https://doi.org/10.32749/nucleodoconhecimento .com.br/administracao/sindrome-de-down

SOUZA, R. T.; MIRANDA, J. C. Inclusão escolar no Brasil: uma análise documental. Boletim de Conjuntura (BOCA), v. 5, n. 13, p. 58-68, 2021.Disponível em: http://revista.ioles.com.br/boca/index.php/revist a/article/view/8.Acesso em: 06 nov. 2021.

TRINDADE, A. S.; NASCIMENTO, M. A. D. Avaliação do desenvolvimento motor em crianças com síndrome de down. Revista Brasileira de Educação Especial, v. 22, p. 577-588, 2016. Disponível em: https://www.scielo.br/j/rbee/a/5LrQLdJKdxVCLgg MTWqSjSn/?lang=pt\&format=html. Acesso em: 18 out. 2021. https://doi.org/10.1590/s1413$\underline{65382216000400008}$

VARELLA, D. Doenças e sintomas: síndrome de Down. Disponível em: https://drauziovarella.uol.com.br/doencas-esintomas/sindrome-de-down/. Acesso em: 07 maio 2019.

VITTO-JUNIOR, J.; LIMA, A. L. S. A inclusão da criança com Síndrome de Down no ensino regular. Revista de Iniciação Científica, Criciúma, v. 9, n. 1, p.76-87, 2011. Disponível em: http://periodicos.unesc.net/iniciacaocientifica/ar ticle/view/1595/1508. Acesso em: 09 ago. 2021.

YAEGASHI, J. G. et al. A inclusão das pessoas com necessidades educacionais especiais: contextualização histórica. Revista Brasileira de Iniciação Científica, Itapetininga, e21001, p. 1-22,
2021.Disponível

em: https://periodicos.itp.ifsp.edu.br/index.php/IC/ar ticle/view/1895. Acesso em: 06 nov. 2021. 